\title{
A PSICOLOGIA PODE SER UMA CIÊNCIA DA MENTE?
}

CAN PSYCHOLOGY BE A SCIENCE OF MIND?²

Burrhus Frederic SKINNER

Muitos psicólogos, como os filósofos antes deles, olharam dentro de si mesmos para a explicação de seus comportamentos. Eles sentiram [felt $]$ sentimentos e observaram processos mentais por meio da introspecção. Entretanto, a introspecção nunca foi muito satisfatória. Os filósofos reconheceram sua inadequação, embora insistindo que esse é, todavia, o único meio de autoconhecimento. Os psicólogos outrora já tentaram aprimorá-la pelo uso de observadores treinados e dos instrumentos de metal [brass instruments] sobre os quais Willian James teve opinião desfavorável. A introspecção já não é mais muito usada. Psicólogos cognitivistas podem ver representações e podem até argumentar que elas são as únicas coisas que podem ser vistas, mas eles não afirmam que veem a si mesmos processando-as. Ao contrário, como os psicanalistas, que enfrentam o mesmo problema com processos que não podem ser vistos porque são inconscientes, voltaram-se para a teoria. Teorias, contudo, precisam de confirmação, e por isso muitos se voltaram para a ciência do cérebro, em que se pode dizer que os processos são inspecionados [inspected], em vez de serem observados instrospectados [introspected]. ${ }^{3}$ Se a mente é "o que cérebro faz",

\footnotetext{
${ }^{1}$ Artigo originalmente publicado em 1990 na revista American Psychologist, v. 45, n. 11, que autorizou a publicação da tradução. Tradução realizada por Nilza Micheletto (Pontifícia Universidade Católica de São Paulo). [N.T.]

${ }^{2}$ Este artigo foi completado em 17 de agosto de 1990, na tarde anterior ao dia da morte do Dr. Skinner. Ele serviu como base para seu discurso na 98a Convenção Anual da Associação Americana de Psicologia em Boston, M.A., e foi escrito para ser publicado no pe-
}

o cérebro pode ser estudado como qualquer outro órgão. Consequentemente, então, a ciência do cérebro deveria dizer-nos o que significa construir uma representação da realidade, armazenar uma representação na memória, converter uma intenção em ação, sentir alegria ou tristeza, tirar uma conclusão lógica, e assim por diante.

Mas o cérebro inicia o comportamento, como se diz que a mente ou eu [self] são capazes de fazer? O cérebro é parte do corpo, e o que ele faz é parte do que o corpo faz. O que o cérebro faz é parte do que deve ser explicado. De onde o conjunto corpo-cérebro [body-cum-brain] vem e por que muda de modo sutil de momento a momento? Nós não podemos encontrar respostas para questões desse tipo no próprio conjunto corpo-cérebro [body-cum-brain], observando introspectivamente ou com instrumentos e métodos da fisiologia.

O comportamento do organismo como um todo é um produto de três tipos de variação e seleção. A primeira, a seleção natural, é responsável pela evolução das espécies e, portanto, pelo comportamento das espécies. Todos os tipos de variação e seleção têm certas falhas, e uma delas é especialmente crítica

riódico American Psychologist. Correspondência relativa a este artigo deve ser endereçada a Julie S. Vargas, presidente da Fundação B. F. Skinner, Caixa Postal 825, Cambridge, M. 02238.

${ }^{3} \mathrm{O}$ autor faz aqui um jogo de palavras: inspected rather than introspected. [N.T.] 
para a seleção natural: ela prepara a espécie para um futuro que se assemelha ao passado selecionado. O comportamento das espécies é efetivo só em um mundo relativamente semelhante ao mundo em que as espécies evoluíram.

Essa falha foi corrigida pela evolução de um segundo tipo de variação e seleção, o condicionamento operante, por meio do qual variações no comportamento do indivíduo são selecionadas por características do ambiente que não são estáveis o suficiente para desempenhar qualquer papel na evolução. No condicionamento operante, o comportamento é reforçado no sentido de ser fortalecido ou tornado mais provável de ocorrer por certos tipos de consequências, que primeiro adquiriram o poder de reforçar por meio da seleção natural.

Uma segunda falha na variação e seleção é crítica para o condicionamento operante: a seleção deve esperar pela variação. Por isso, o processo é geralmente lento. Isso não foi um problema para a seleção natural, porque a evolução poderia levar milhões de anos, mas um repertório de comportamentos operantes deve ser construído durante o tempo de uma vida. O condicionamento operante deve resolver o "problema de uma primeira ocorrência": como e por que respostas ocorrem antes de elas terem sido reforçadas?

O problema foi solucionado em parte pela evolução de processos por meio dos quais os indivíduos aproveitam comportamentos já adquiridos por outros. A imitação é um exemplo disso. Ela frequentemente põe o imitador em contato com as consequências reforçadoras responsáveis pelo comportamento imitado. O comportamento do imitador é "preparado" ["primed"], no sentido de que é feito para ocorrer pela primeira vez e geralmente quando é provável de ele ser reforçado.

Nesse ponto, a espécie humana parece ter dado um passo evolutivo único. Outras espécies também imitam, mas, se elas fornecem o modelo do comportamento a ser imitado, é só como produto da seleção natural. A consequência de dar modelo [modeling], o comportamento do imitador, é muito remota para servir como reforçador operante. Só na espécie humana o comportamento do imitador reforça dar modelo.

As espécies passaram por outra mudança evolutiva única quando sua musculatura vocal começou a ser controlada pelo operante e quando o comportamento vocal começou a ser modelado [shaped] e mantido por suas consequências reforçadoras. Pessoas podiam, então, preparar [prime] o comportamento de outros dizendo-lhes o que fazer, bem como mostrando-lhes. (Em um presumível passo seguinte, consequências reforçadoras temporárias foram adicionadas para tornar mais provável que o comportamento se mantivesse fortalecido até que a consequência para a qual ele foi preparado [primed] pudesse entrar em ação. Adicionar temporariamente reforçamentos desse modo é ensinar.)

Um conselho pode ser útil em mais de uma ocasião e ele é frequentemente dado e ensinado de tal modo que passa de pessoa para pessoa ou de geração a geração. Máximas ("grandes ditados") ["great saying"]) e provérbios ("ditados populares") ["saying put forth"] são exemplos disso. Eles descrevem melhor contingências de reforçamento - um centavo (bem como também muitas outras coisas) economizado é um centavo (bem como muitas outras coisas) ganho. Regras 
são dizeres transmitidos pelos grupos, usualmente com consequências reforçadoras mais fortes. As leis de governos e religiões descrevem as contingências de reforçamento (usualmente negativas) mantidas por essas instituições. Elas têm o efeito de advertências: pela obediência à lei, uma pessoa se esquiva de comportar-se de modos que poderiam ser punidos. As leis da fisica e da química ("regras para ação efetiva”) descrevem as contingências de reforçamento mantidas pelo ambiente fisico.

Dar modelos [modeling], dizer e ensinar são as funções dos ambientes sociais chamados culturas. Diferentes culturas emergem de diferentes contingências de variação e seleção e diferem umas das outras na extensão em que ajudam seus membros a solucionar seus problemas. Os membros que os resolvem têm mais chances de sobreviver, e com eles sobrevivem as práticas da cultura. Em outras palavras, culturas evoluem, em uma terceira espécie de variação e seleção. (Culturas que modelam e mantêm comportamento "operante" são exclusivamente humanas. Sociedades animais têm muitas características semelhantes, mas apenas como produto de contingências de sobrevivência.) A evolução cultural não é um processo biológico, mas, como um tipo de variação e seleção, ela tem as mesmas falhas. O fato de que uma cultura prepara o grupo apenas para um mundo que se assemelha ao mundo em que a cultura evoluiu é a fonte de nossa preocupação atual com o futuro de uma Terra habitável.

O processo de variação e seleção tem uma terceira falha: variações são randômicas e contingências de seleção, acidentais. $\mathrm{O}$ que evoluiu não é uma única espécie desenvolvendo-se vagarosamente, mas milhões de diferentes espécies, competindo umas com as outras por um lugar no mundo. O produto do condicionamento operante não é um único repertório coerente, mas milhares de repertórios menores, cujos conflitos devem de algum modo ser resolvidos. A evolução do ambiente social produziu não uma única cultura, mas muitas, frequentemente conflitantes entre si.

Embora o controle operante da musculatura vocal seja exclusivo da espécie humana, isso raramente ou quase nunca é citado como característica distintiva. É mais provável que seja citada a presença ou a ausência da "consciência" ou "inteligência consciente". O papel desempenhado pela mente/cérebro tem sido sempre um problema na comparação das espécies. Descartes excluiu o "homem" de seu modelo mecânico de um organismo, e Wallace, diferentemente de Darwin, não acreditava que a evolução poderia explicar a mente humana. Cientistas do cérebro expressaram reservas semelhantes. Teóricos evolucionistas sugeriram que "inteligência consciente" é um traço evolutivo, mas eles nunca mostraram como uma variação não física poderia surgir para ser selecionada por contingências fisicas de sobrevivência. (A sugestão simplesmente movimenta a aborrecida distinção físico-metafisico um passo além.) Tem-se dito que nós nunca podemos saber como uma mente consciente evoluiu, porque nada poderia sobreviver para os paleontologistas descobrirem, mas o controle operante da musculatura vocal, o mostrar, o dizer e o ensinar que resultaram disso sobre- 
viveram, e é possível que eles expliquem a introspecção e também o que é "visto" com sua ajuda.

A raiz spect ${ }^{4}$ sugere visão. Nós dizemos que "olhamos" e "vemos" o que está acontecendo dentro de nós mesmos, mas jamais se descobriu qualquer olho interno. Podemos evitar especificar um tipo de órgão dizendo observe, ${ }^{5}$ notice, ou note, em vez de vemos, e é significativo que observe, notice e note, e, menos comumente, remark, signifiquem tanto dizer quanto ver. Muito depende do que significa sentir [to sense] qualquer parte do mundo com qualquer tipo de órgão. Teorias de input-output, como no modelo estímulo-resposta ou de processamento de informação, fazem uma aguda distinção entre sentir [sensing] e fazer [doing]. Diz-se que nós sentimos o mundo antes de agir sobre ele. Entretanto, a análise experimental do comportamento assinala um papel muito diferente para o estímulo. Uma resposta operante é mais provável de ocorrer na presença do estímulo que estava presente quando foi reforçada. Sentir é tanto um produto da variação e seleção como o fazer. É parte do fazer. Por razões semelhantes, a seleção natural explica a presteza com que animais respondem instantaneamente a características do ambiente que foram cruciais para a sobrevivência de suas espécies, tais como a visão, o som ou o cheiro da comida, ou a oportunidade sexual, ou a ameaça de perigo, incluindo o perigo do que não é familiar. Os animais presumivelmente "recebem" todos os estímulos que os impingem,

\footnotetext{
${ }^{4}$ Spect como raiz das palavras inspecionare, introspectar (inspect, introspect). [N.T.]

${ }^{5}$ Aqui, foram mantidos os termos em inglês, porque a tradução em português não permite manter os dois sentidos das palavras em inglês: ver e dizer. [N.T.]
}

mas é possível que eles respondam somente àqueles que desempenharam um papel nas contingências de seleção. (Nós não podemos saber se animais não verbais vêm estímulos que nunca tenham desempenhado tal papel, porque nós teríamos de arranjar contingências contendo tais estímulos para descobrir.) Nós podemos ver coisas com relação às quais não temos nenhuma ação prática (por exemplo, vemos coisas que estão fora de nosso alcance), mas possivelmente só porque falamos sobre elas. Ver coisas sem levar a uma ação posterior é estar ciente [aware] delas. (A raiz de ciente [aware] é também encontrada em atento [wary]; estamos atentos para as coisas que foram parte de contingências negativas de seleção.) A palavra consciente [conscious], usada mais frequentemente do que ciente [aware], significa coconhecimento (do latim: con-science), ou "conhecimento com outros" - uma alusão às contingências verbais necessárias para ser consciente [conscious].

Tudo isso é particularmente importante quando o que nós vemos está dentro de nosso próprio corpo, o tipo de ver para o qual nós reservamos usualmente a palavra introspecção. Mas o que nós realmente vemos? Psicólogos que estão incomodados com a natureza metafísica da vida mental frequentemente dizem que o que nós vemos por meio da introspecção deve ser o cérebro, mas isso é improvável. Nós não temos nervos sensoriais indo para partes importantes do cérebro; um cirurgião pode operar [o cérebro] sem anestesia. Nenhuma contingência de seleção teria promovido a evolução de tais nervos antes do advento do comportamento verbal, e isso aconteceu muito tarde na evolução da espécie. É mais provável que o que nós vemos por meio da introspecção sejamos 
estágios iniciais de nosso comportamento, os estágios que ocorrem antes de o comportamento começar a agir no ambiente.

Sentir [sensing] é um desses estágios; nós vemos coisas antes de respondermos a elas de qualquer outro modo, e nós vemos que nós as estamos vendo quando não estamos fazendo mais nada. As contingências necessárias são fornecidas pelas pessoas que nos perguntam se estamos vendo coisas. O próprio começo da ação é outro estágio inicial. Isso não levanta qualquer questão sobre a disponibilidade dos nervos sensoriais, porque nós deveríamos ser capazes de ver estágios iniciais com os nervos necessários para a ação completa. (É também possível que às vezes não estejamos introspectando [introspecting] nada, mas estamos respondendo ao contexto [setting] externo, como se "eu estou indo..." significasse "em situações como essa eu usualmente vou....").

Diz-se que os gregos descobriram a mente, mas é mais provável que eles tenham sido os primeiros a falar extensivamente sobre o que viam dentro de si mesmos, e assim construíram as contingências necessárias para a introspecção. Os Diálogos da Academia de Platão teriam criado contingências sobre as quais mais e mais inícios do comportamento poderiam ser vistos. Deve ter sido um mundo intrincado. Nós vemos o mundo público ao redor de nós, mas também o sentimos, ouvimos, saboreamos e cheiramos. Nós não fazemos nada com um mundo interno, mas o "vemos". Não é surpresa que os gregos o chamaram de metafísico.

Infelizmente, o que eles viam ocorria no exato tempo e lugar, de modo a ser confundido com uma causa do que eles faziam, e por isso foi fácil supor que eles tinham des- coberto um eu [self] ou mente originador. Todavia, o que eles viam era simplesmente uma parte inicial do que então faziam; entretanto, isso não era mais uma causa do resto do que eles faziam do que o movimento para trás do jogador de golfe é a causa da tacada que lança a bola. Partes iniciais do comportamento afetam partes posteriores, mas é o comportamento como um todo que é o produto da variação e seleção.

Tal análise da introspecção e da "consciência" ["consciousness"] introspectada precisa, certamente, de consideração cuidadosa, mas todo esforço deveria ser feito para preservá-la, porque ela dispensa qualquer necessidade de remeter a um tipo especial de conhecimento ou a um tipo especial de matéria conhecida. Permanece dentro do mundo da física e da química e das ciências de variação e seleção. Evita qualquer sugestão de uma ruptura no processo de variação e seleção.

Duas ciências estabelecidas, cada uma com um objeto claramente definido, fazem referência ao comportamento humano. Uma é a fisiologia do conjunto corpo-cérebro, uma questão de órgãos, tecidos e células, e mudanças elétricas e químicas que ocorrem neles. A outra é um grupo de três ciências relativas à variação e seleção que determina a condição daquele conjunto corpo-cérebro em qualquer momento: a seleção natural do comportamento das espécies (etologia), o condicionamento operante do comportamento do indivíduo (análise do comportamento) e a evolução dos ambientes sociais que prepara [prime] o comportamento operante e que amplia consideravelmente sua extensão (uma parte da antropologia). As três 
poderiam ser relacionadas da seguinte maneira: a fisiologia estuda o produto do que as ciências da variação e seleção estudam a produção. O corpo trabalha como trabalha por causa das leis da física e da química; ele faz $o$ que ele faz por sua exposição a contingências de variação e seleção. A fisiologia nos diz como o corpo trabalha; as ciências da variação e da seleção nos dizem por que esse corpo trabalha desse modo.

As duas ciências observam princípios causais muito diferentes. $\mathrm{O}$ conjunto corpo-cérebro obedece às leis da física e da química. Ele não tem liberdade e não faz escolhas. Nenhuma outra visão do "homem-máquina" (nesse caso, uma máquina bioquímica) foi tão bem apoiada. Alguns cientistas do cérebro argumentaram que o cérebro deve ter características estruturais que possibilitam a liberdade de escolha, a criatividade e algo semelhante, mas, fazendo assim, eles argumentam a partir do que o cérebro faz mais que de sua estrutura. Tem sido dito também que variação e seleção poderiam ocorrer no cérebro, mas, embora o cérebro, como qualquer outra parte do corpo, experimente variações, as contingências de seleção estão no ambiente.

Quanto mais nós sabemos sobre o conjunto corpo-cérebro como uma máquina bioquímica, menos interessante isso se torna em sua referência ao comportamento. Se há liberdade, ela poderá ser encontrada na aleatoriedade das variações. Se novas formas de comportamento são criadas, elas são criadas pela seleção. As falhas na variação e seleção são uma fonte de problemas fascinantes. Nós devemos nos adaptar a situações novas, resolver conflitos e encontrar rápidas soluções. Uma estrutura bioquímica submetida a leis não faz nada disso.
Simulações computadorizadas do comportamento humano são máquinas eletrônicas projetadas para se comportar como a máquina bioquímica do corpo se comporta. Nós sabemos como elas foram planejadas e construídas e, portanto, não levantamos questões sobre sua origem. Pela mesma razão, entretanto, simulações não têm interesse particular para analistas do comportamento. As coisas interessantes na vida vêm dos caprichos da variação e seleção, na construção da máquina.

A análise do comportamento é a única das três ciências da variação e seleção a ser estudada detalhadamente em laboratório. Os etologistas observam o comportamento em campo e reconstroem a evolução a partir de evidência que sobrevive de tempos remotos. A etologia é apoiada por uma ciência de laboratório, a genética, mas não se produziu ainda uma nova espécie com um repertório de comportamento inato, em condições de laboratório. A evolução de uma cultura é também primordialmente um objeto de inferências da história. É a velocidade que faz a diferença; só o condicionamento operante ocorre de maneira suficientemente rápida para ser observado do começo ao fim. Pela mesma razão, é a única das três ciências a ser usada para propósitos práticos no dia a dia.

Por isso, é dificil entender por que o condicionamento operante não tem atraído mais atenção. O papel da variação e seleção no comportamento do indivíduo é muitas vezes simplesmente ignorado. A sociologia, por exemplo, pula do sócio- para o bio-, ignorando a ligação individual. Muitos dos psicólogos que têm estudado o comportamento também negligenciaram a variação e seleção. A Lei do Efeito, de Thorndike, chegou perto, 
mas seu experimento sugeriu que variações eram tentativas e consequências eram erros. Watson, Lashley e Hull apelaram para a formação de hábito e estímulo e resposta. O propósito de Tolman, como orientação com relação a fins ou utilidade subjetiva esperada, projetou cópias de consequências passadas no futuro como atrações que parecem puxar o comportamento.

A análise do comportamento é a mais jovem das três ciências (as teorias da seleção natural e a evolução das culturas datam da metade do século XIX, e a análise do comportamento, só do fim do primeiro terço do século XX), mas a imaturidade não explicará por que ela tão frequentemente tem sido negligenciada. A melhor explicação deve ser que seu campo foi ocupado por muito tempo por aquela extraordinariamente intrigante teoria de uma mente ou eu [self] originador interno.

Nós não falamos a linguagem da ciência do cérebro e da análise do comportamento no nosso dia a dia. Não podemos ver o cérebro e conhecemos muito pouco sobre a história de variação e seleção responsável por uma ocorrência de comportamento. Ao contrário, usamos uma linguagem que existia muito antes de quaisquer filósofos ou cientistas. Essa linguagem é chamada apropriadamente vernacular. A palavra vernacular significa, como a raiz significava para os romanos, a linguagem doméstica, do dia a dia. Nós todos a falamos. É a linguagem dos jornais, revistas, livros, rádio e televisão. Quando falam do comportamento do indivíduo, ela é a linguagem dos cientistas comportamentais - psicólogos, sociólogos, antropólogos, cien- tistas políticos e economistas. William James escreveu Princípios de Psicologia na linguagem vernacular. Os behavioristas falam-na em seu dia a dia (e jovens behavioristas devem aprender a fazer isso sem constrangimento).

A linguagem vernacular refere-se a vários sentimentos e estados da mente. Em inglês, por exemplo, nós dizemos que fazemos o que sentimos vontade de fazer [feel like doing] ou que precisamos fazer [need to do] para satisfazermos nossos desejos. Nós dizemos que estamos famintos e estamos pensando em obter algo para comer. É fácil supor que as referências são para uma mente iniciadora, mas, como vimos, as alusões úteis são para as contingências anteriores de seleção ou para os começos [beginnings] de ação. Da frase "eu estou com fome" nós inferimos que a pessoa não comeu há algum tempo e provavelmente comerá quando a comida estiver disponível. Da frase "eu estou pensando em obter alguma coisa para comer" nós inferimos a probabilidade de fazer alguma coisa que torne a comida disponível.

Mediante o uso da linguagem vernacular, com suas alusões à história pessoal e à probabilidade de ação, a psicologia emergiu como uma profissão efetiva, essencial e altamente respeitada. A tentativa de usar referências aparentes a uma mente iniciadora e converter a linguagem vernacular em linguagem da ciência foi, entretanto, um erro. Watson e outros dos primeiros behavioristas pensaram que o erro estava no uso da introspecção. Quão bem os sentimentos poderiam ser sentidos e os processos mentais ser vistos? Antecipando o positivismo lógico, eles argumentaram que um evento visto por uma única pessoa não tem lugar na ciência. Entretanto, o problema não era a introspecção; era 
o eu [self] ou a mente iniciadora aos quais a introspecção parecia dar acesso.

No contato face a face com outra pessoa, referências a um eu [self] iniciador são inevitáveis. Há um "você” e há um "eu” [I]. Eu vejo o que "você" faz e ouço o que "você" diz, e você vê o que "eu" faço e ouve o que "eu" digo. Nós não vemos as histórias da seleção responsáveis pelo que é feito, e por isso inferimos uma origem interna, mas o uso bem-sucedido da linguagem vernacular na prática da psicologia não oferece apoio para seu uso na ciência. Em uma análise científica, as histórias de variação e seleção desempenham o papel de iniciador. Não há lugar em uma análise científica do comportamento para a mente ou eu [self].

O que, então, podemos fazer do fato de que por 100 anos psicólogos tentaram construir apenas tal ciência da mente? E o que dizer das análises brilhantes que têm sido feitas da inteligência ou das reivindicações acerca do valor do conceito de utilidade esperada subjetiva ou das equações que foram escritas para descrever o espaço psicológico? Essas investigações fizeram parte da busca de algo que não existe? Parece que sim, mas tudo não está perdido. A inteligência, embora nunca introspectada [introspectible], é claramente uma inferência de uma amostra de comportamento estabelecido em testes de inteligência, e uma análise de diferentes tipos de inteligência é uma análise de diferentes tipos de comportamento. A expectativa [expectation], outro tipo de "spection" [que tem o mesmo radical de "spection"], não pode significar ver o futuro e deve ser o produto de contingências passadas de reforçamento. Utilidade [utility] significa algo proveitoso [usefulness], ou útil, a ação ou meios de fazer algo de tal modo que as consequências se sigam. O espaço psicológico é espaço real quando ele se torna parte do controle das contingências de reforçamento; a questão é qual a extensão em que um estímulo presente quando uma resposta é reforçada se generaliza de tal modo que estímulos semelhantes, que não estavam presentes, exerçam controle. Em resumo, psicólogos têm analisado não intencionalmente contingências de reforçamento, as próprias contingências responsáveis pelo comportamento equivocadamente atribuído a um originador interno.

Mas o que dizer de filósofos ilustres que através dos séculos tentaram seguir as injunções do Oráculo de Delfos e conhecer a si mesmos por meio da introspecção? Há uma justificação semelhante ou eles teriam inutilmente perseguido uma esperança ilusória? Dizer isso poderia parecer um pouco de arrogância se não houvesse um paralelo esclarecedor. Homens e mulheres igualmente ilustres procuraram por muito tempo e com grande dedicação por outro Criador, escrito dessa vez com um "C" maiúsculo, cujas realizações relatadas estão sendo também questionadas pela ciência. Foi Darwin, certamente, quem fez a diferença. Isso vigora tanto para a origem do comportamento como para a origem das espécies. Quase um século e meio depois, a evolução ainda não é entendida plenamente. Ela é vigorosamente combatida pelos defensores de um criador. Como resultado, ainda é impossível ensinar biologia apropriadamente em muitas escolas americanas. Foi proposto ensinar em seu lugar uma ciência criacionista. O papel da variação e seleção no comportamento do indivíduo sofre da mesma oposição. A ciência cognitiva é uma ciência criacionista da psicologia, dado 
que ela luta para manter a posição de uma mente ou eu [self].

A história da psicologia é informativa. Ela começou, 100 anos atrás, com uma busca introspectiva da mente. Watson atacou a introspecção em seu manifesto de 1913, e por essa ou outras razões a introspecção foi essencialmente abandonada. Behavioristas voltaram-se para o estudo do comportamento pelo comportamento como tal, e psicólogos não behavioristas voltaram-se para o comportamento de professores, estudantes, terapeutas, clientes, crianças ficando mais velhas ano a ano, grupos de pessoas, e assim por diante.

Psicólogos cognitivistas tentaram restaurar o status quo. O behaviorismo, eles declararam, estava morto. Eles não poderiam querer dizer que psicólogos não estudavam mais o comportamento de animais em laboratório e de professores, estudantes, terapeutas, clientes, e assim por diante. $\mathrm{O}$ que eles esperavam que estivesse morto era o recurso à seleção por consequências para explicação do comportamento. A mente ou, em sua ausência, o cérebro deve ser recolocado em sua posição de direito.

Por sua semelhança com a linguagem vernacular, a psicologia cognitivista foi fácil de entender, e então a chamada revolução cognitivista foi durante um tempo bem-sucedida. Isso pode ter acelerado a velocida- de com que os analistas do comportamento afastaram-se do sistema [establishment] psicológico, fundando suas próprias associações, realizando seus próprios encontros, publicando seus próprios periódicos. Eles foram acusados de construir seu próprio gueto, mas simplesmente estavam aceitando o fato de que tinham pouco a ganhar com o estudo de uma mente criativa.

A psicologia cognitiva ficou como a parceira científica de uma profissão e a base científica da psicologia educacional, clínica, do desenvolvimento, social e de muitos outros campos. A ajuda que ela lhes deu não foi notável. Uma versão da linguagem vernacular refinada pelo estudo da vida mental dificilmente é mais útil que a versão leiga, especialmente quando a teoria começou a substituir a introspecção. Muito mais útil teria sido a análise do comportamento. Ela teria ajudado de dois modos: esclarecendo as contingências de reforçamento às quais a linguagem vernacular se refere e tornando possível planejar ambientes melhores - ambientes pessoais que resolveriam problemas existentes e ambientes maiores, ou culturas nas quais haveria menos problemas. Uma maior compreensão da variação e seleção significará uma profissão mais bem-sucedida, mas se a análise do comportamento será chamada de psicologia é uma questão que o futuro decidirá. 